ORIGINAL ARTICLE

\title{
Use of cellular telephones and brain tumour risk in urban and rural areas
}

\author{
L Hardell, M Carlberg, K Hansson Mild
}

Occup Environ Med 2005;62:390-394. doi: 10.1136/oem.2004.017434

See end of article for authors' affiliations

.....................

Correspondence to: Prof. L Hardell, Department of Oncology, University Hospital, SE-701 85 Örebro, Sweden; lennart. hardell@orebroll.se

Accepted 1 December 2004

\begin{abstract}
Aims: To investigate the association between the use of cellular or cordless telephones and the risk for brain tumours in different geographical areas, urban and rural.

Methods: Patients aged 20-80 years, living in the middle part of Sweden, and diagnosed between 1 January 1997 and 30 June 2000 were included. One control matched for sex and age in five year age groups was selected for each case. Use of different phone types was assessed by a questionnaire.

Results: The number of participating cases was 1429; there were 1470 controls. An effect of rural living was most pronounced for digital cellular telephones. Living in rural areas yielded an odds ratio (OR) of 1.4 (95\% $\mathrm{Cl} 0.98$ to 2.0 ), increasing to $3.2(95 \% \mathrm{Cl} 1.2$ to 8.4 ) with $>5$ year latency time for digital phones. The corresponding ORs for living in urban areas were 0.9 (95\% $\mathrm{Cl} 0.8$ to 1.2 ) and 0.9 (95\% $\mathrm{Cl} 0.6$ to 1.4 ), respectively. This effect was most obvious for malignant brain tumours.

Conclusion: In future studies, place of residence should be considered in assessment of exposure to microwaves from cellular telephones, although the results in this study must be interpreted with caution due to low numbers in some of the calculations.
\end{abstract}

A difference in the power output level from mobile phones between urban and rural areas has recently been shown. ${ }^{1}$ This is caused by adaptive power control (APC) in the cellular telephone and is regulated by the distance between base stations. Thus, in areas with a long distance between base stations, usually rural areas, the output power level is higher than in more densely populated areas-that is, urban areas, with a shorter distance between base stations. APC is used for the Global System for the Mobile Communication (GSM) network. When the Nordic Mobile Telephone System (NMT) started in Sweden in 1981, the highest power was used all the time by the mobile phones. With increasing numbers of users of the NMT, phones in this system were regulated by APC, but only if they were very close to the base station and then only in one step.

In previous epidemiological studies we found an association between use of cellular telephones and brain tumours. ${ }^{23}$ However, for salivary gland tumours no association was found, although the parotid gland is located in an area with high exposure to microwaves from cellular telephones compared with other anatomical sites. ${ }^{4}$ These and other results on this topic have been recently reviewed elsewhere ${ }^{5}$ and will not be further discussed here.

In epidemiological studies assessment of microwave exposure is usually based on type of phone (NMT, GSM, and cordless), and years and cumulative number of hours of use. There is a variation in specific absorption rate (SAR) between the different types of cellular telephones. However, this information is not easily available since subjects can seldom remember the brand names of the cellular phones used over time. Moreover, information on SAR is usually not available from the manufacturers.

During cellular phone calls, radio frequency (RF) signals in the range of 400 to 2000 megaHertz (MHz) are used. In Sweden the analogue NMT system was introduced in 1981 operating at $450 \mathrm{MHz}$, often in a car with a fixed external antenna, but from 1984 the first portable analogue phones were available. The NMT $900 \mathrm{MHz}$ system operated in Sweden between 1986 and 2000. The digital GSM system started in 1991 and is the most common phone since the end of the 1990s in Sweden. Moreover desktop cordless telephones have been used in Sweden since 1988. The analogue system in the $800-900 \mathrm{MHz}$ RF range was initially used, but now digital cordless telephones that operate at $1900 \mathrm{MHz}$ are available.

One interesting aspect with regard to exposure is the different output power from cellular telephones in urban and rural areas due to APC. In our previous study the results were based on 1429 cases (88\%) and 1470 controls (91\%) that answered the questionnaire. ${ }^{2}$ In this further analysis of the material we grouped the place of residence for the cases and controls into urban and rural areas.

\section{METHODS}

The details of the study design have been published elsewhere $^{2}$ and only a brief summary is given here. The geographical study area was the middle part of Sweden, and encompassed patients aged 20-80 years who were diagnosed between 1 January 1997 and 30 June 2000. Histopathology and information on tumour localisation were obtained from the cancer registry and neuroradiology reports. One control for each case was drawn from the population register, matched for sex and age (five year age groups) and living in the same geographical area as the cases. The ethical committees approved the investigation.

Use of cellular and cordless phones was assessed by a questionnaire which also included lifetime work history. The answers were supplemented over the phone using a written protocol. Mean number of daily calls and minutes were asked for to calculate the cumulative use in hours for all years. Data were also collected on use in a car with a fixed external antenna or outside a car using a hands-free device with an earpiece, both taken as no exposure to microwaves. The ear

Abbreviations: APC, adaptive power control; $\mathrm{Cl}$, confidence interval; GSM, Global System for Mobile Communication; $\mathrm{H}$, homogeneity region; MHz, megaHertz; NMT, Nordic Mobile Telephone System; OR, odds ratio; RF, radio frequency; SAR, specific absorption rate; SEl, socioeconomic index 


\section{Main messages}

- Adaptive power control regulates the output power level from cellular telephones, mainly the digital system, with the highest level in areas with a long distance between base stations.

- There was a higher risk for brain tumours in users of digital cellular telephones in rural areas than in urban areas.

most frequently used during cellular phone calls was noted, or whether both ears were used equally.

The Swedish population register contains information on present municipality for all residents. The municipalities are classified by Statistics Sweden in so called homogeneity regions, six categories depending on the population density, and the number of inhabitants in the nearest vicinity of the main city in that municipality. ${ }^{6}$ According to this official homogeneity region classification, the two highest density categories $(\mathrm{Hl}, \mathrm{H} 2)$ include only the largest cities of Sweden, Stockholm, Göteborg, and Malmö/Lund. H3 consists of municipalities with more than 90000 inhabitants within a $30 \mathrm{~km}$ radius from the centre of that municipality. H4 includes municipalities with more than 27000 , but less than 90000 inhabitants from the centre of that municipality and
Policy implications

- In future studies, place of residence should be considered in assessment of exposure to microwaves from cellular telephones.

also more than 300000 inhabitants within a $100 \mathrm{~km}$ radius from the same centre. $\mathrm{H} 5$ is identical to $\mathrm{H} 4$ except that there are less than 300000 inhabitants from the centre of the municipality. Finally, H6 consists of municipalities with less than 27000 inhabitants within a radius of $30 \mathrm{~km}$ from the centre. Thus, we used these official statistics for grouping of the subjects in urban or rural areas.

Unconditional logistic regression analysis was used to calculate odds ratios (OR) and 95\% confidence intervals (CI) (Stata/SE 8.2 for Windows; StataCorp, College Station, TX). The material was divided into two groups, exposed and unexposed. The exposed cases and controls were further divided according to phone type: analogue, digital, and cordless. The unexposed group consisted of cases and controls without exposure to cellular or cordless telephones. Adjustment was made for sex, age, and socioeconomic index (SEI) code. In the analysis of dose-response effect the material was divided in two groups with median number of hours among controls as cut-off. Latency (tumour induction

Table 1 Odds ratios and $95 \%$ confidence intervals for brain tumours for the whole study area $(\mathrm{H} 1-\mathrm{H} 6)$, and urban $(\mathrm{H} 1-\mathrm{H} 3)$ and rural areas $(\mathrm{H} 4-\mathrm{H} 6)$

\begin{tabular}{|c|c|c|c|c|c|c|c|c|c|}
\hline & \multicolumn{3}{|c|}{$>1$ year latency } & \multicolumn{3}{|c|}{$>5$ year latency } & \multicolumn{3}{|c|}{$>10$ year latency } \\
\hline & $\mathrm{Ca} / \mathrm{Co}_{0}$ & OR & $95 \% \mathrm{Cl}$ & $\mathrm{Ca} / \mathrm{Co}$ & OR & $95 \% \mathrm{Cl}$ & $\mathrm{Ca} / \mathrm{Co}_{0}$ & OR & $95 \% \mathrm{Cl}$ \\
\hline \multicolumn{10}{|l|}{ Analogue } \\
\hline $\mathrm{Hl}-\mathrm{H} 6$ & $247 / 218$ & 1.3 & 1.04 to 1.6 & $160 / 135$ & 1.4 & 1.03 to 1.8 & $61 / 44$ & 1.6 & 1.1 to 2.5 \\
\hline $\mathrm{H} 1-\mathrm{H} 3$ & $167 / 148$ & 1.3 & 0.995 to 1.7 & $110 / 96$ & 1.3 & 0.9 to 1.8 & $40 / 31$ & 1.5 & 0.9 to 2.6 \\
\hline $\mathrm{H} 4-\mathrm{H} 6$ & $80 / 70$ & 1.3 & 0.9 to 2.0 & $50 / 39$ & 1.5 & 0.9 to 2.4 & $21 / 13$ & 1.9 & 0.9 to 3.9 \\
\hline \multicolumn{10}{|l|}{$\leqslant 85 \mathrm{~h}$} \\
\hline $\mathrm{H} 1-\mathrm{H} 6$ & $134 / 115$ & 1.3 & 0.995 to 1.7 & $69 / 51$ & 1.5 & 1.0 to 2.2 & $12 / 13$ & 1.0 & 0.5 to 2.3 \\
\hline $\mathrm{H} 1-\mathrm{H} 3$ & $88 / 73$ & 1.4 & 0.97 to 1.9 & $48 / 35$ & 1.5 & 0.9 to 2.4 & $7 / 10$ & 0.8 & 0.3 to 2.0 \\
\hline $\mathrm{H} 4-\mathrm{H} 6$ & $46 / 42$ & 1.2 & 0.8 to 2.0 & $21 / 16$ & 1.5 & 0.7 to 3.0 & $5 / 3$ & 1.9 & 0.4 to 8.2 \\
\hline \multicolumn{10}{|l|}{$>85 \mathrm{~h}$} \\
\hline $\mathrm{H} 1-\mathrm{H} 6$ & $113 / 103$ & 1.3 & 0.95 to 1.8 & $91 / 84$ & 1.3 & 0.9 to 1.8 & $49 / 31$ & 1.9 & 1.2 to 3.1 \\
\hline $\mathrm{H} 1-\mathrm{H} 3$ & $79 / 75$ & 1.2 & 0.9 to 1.8 & $62 / 61$ & 1.2 & 0.8 to 1.8 & $33 / 21$ & 1.9 & 1.1 to 3.5 \\
\hline $\mathrm{H} 4-\mathrm{H} 6$ & $34 / 28$ & 1.4 & 0.8 to 2.5 & $29 / 23$ & 1.5 & 0.8 to 2.7 & $16 / 10$ & 1.9 & 0.8 to 4.3 \\
\hline \multicolumn{10}{|l|}{ Digital } \\
\hline $\mathrm{Hl}-\mathrm{H} 6$ & $423 / 433$ & 1.0 & 0.9 to 1.3 & $66 / 66$ & 1.1 & 0.8 to 1.6 & - & - & - \\
\hline $\mathrm{HI}-\mathrm{H} 3$ & $303 / 340$ & 0.9 & 0.8 to 1.2 & $49 / 60$ & 0.9 & 0.6 to 1.4 & - & - & - \\
\hline $\mathrm{H} 4-\mathrm{H} 6$ & $120 / 93$ & 1.4 & 0.98 to 2.0 & $17 / 6$ & 3.2 & 1.2 to 8.4 & - & - & - \\
\hline \multicolumn{10}{|l|}{$\leqslant 55 \mathrm{~h}$} \\
\hline $\begin{array}{l}\mathrm{H} 1-\mathrm{H} 6 \\
\mathrm{H} 1-\mathrm{H} 3\end{array}$ & $\begin{array}{l}230 / 217 \\
162 / 167\end{array}$ & $\begin{array}{l}1.1 \\
10\end{array}$ & $\begin{array}{l}0.9 \text { to } 1.4 \\
0.8 \text { to } 1.3\end{array}$ & $\begin{array}{l}17 / 26 \\
11 / 23\end{array}$ & $\begin{array}{l}0.7 \\
0.5\end{array}$ & $\begin{array}{l}0.4 \text { to } 1.4 \\
0.3 \text { to } 1.1\end{array}$ & - & _- & - \\
\hline $\mathrm{H} 4-\mathrm{H} 6$ & $68 / 50$ & 1.5 & 0.97 to 2.3 & $6 / 3$ & 2.2 & 0.5 to 9.0 & - & - & - \\
\hline \multicolumn{10}{|l|}{$\begin{aligned} & H 4-10 \\
&>55 \mathrm{~h}\end{aligned}$} \\
\hline $\mathrm{H} 1-\mathrm{H} 6$ & $193 / 216$ & 0.9 & 0.7 to 1.2 & $49 / 40$ & 1.4 & 0.9 to 2.1 & - & - & - \\
\hline $\mathrm{HI}-\mathrm{H} 3$ & $141 / 173$ & 0.9 & 0.6 to 1.1 & $38 / 37$ & 1.1 & 0.7 to 1.9 & - & - & - \\
\hline $\mathrm{H} 4-\mathrm{H} 6$ & $52 / 43$ & 1.3 & 0.8 to 2.1 & $11 / 3$ & 4.2 & 1.1 to 16 & - & - & - \\
\hline \multicolumn{10}{|l|}{ Cordless } \\
\hline $\mathrm{Hl}-\mathrm{H} 6$ & $402 / 396$ & 1.1 & 0.9 to 1.3 & $164 / 129$ & 1.4 & 1.1 to 1.8 & $10 / 10$ & 1.1 & 0.4 to 2.6 \\
\hline $\mathrm{H} 1-\mathrm{H} 3$ & $283 / 297$ & 1.0 & 0.8 to 1.3 & $117 / 97$ & 1.3 & 0.97 to 1.8 & $7 / 7$ & 1.1 & 0.4 to 3.1 \\
\hline $\mathrm{H} 4-\mathrm{H} 6$ & 119/99 & 1.3 & 0.9 to 1.8 & $47 / 32$ & 1.7 & 1.01 to 2.8 & $3 / 3$ & 1.1 & 0.2 to 5.5 \\
\hline \multicolumn{10}{|l|}{$\leqslant 183 \mathrm{~h}$} \\
\hline $\mathrm{H} 1-\mathrm{H} 6$ & $183 / 208$ & 0.9 & 0.7 to 1.2 & $50 / 47$ & 1.2 & 0.8 to 1.8 & $0 / 5$ & - & - \\
\hline $\mathrm{H} 1-\mathrm{H} 3$ & $126 / 153$ & 0.9 & 0.7 to 1.2 & $34 / 35$ & 1.1 & 0.7 to 1.8 & $0 / 4$ & - & - \\
\hline $\mathrm{H} 4-\mathrm{H} 6$ & $57 / 55$ & 1.1 & 0.7 to 1.7 & $16 / 12$ & 1.5 & 0.7 to 3.3 & $0 / 1$ & - & - \\
\hline \multicolumn{10}{|l|}{$>183 \mathrm{~h}$} \\
\hline $\mathrm{H} 1-\mathrm{H} 6$ & $219 / 188$ & 1.2 & 0.99 to 1.6 & $114 / 82$ & 1.5 & 1.1 to 2.1 & $10 / 5$ & 2.1 & 0.7 to 6.3 \\
\hline $\mathrm{H} 1-\mathrm{H} 3$ & $157 / 144$ & 1.1 & 0.9 to 1.5 & $83 / 62$ & 1.4 & 1.002 to 2.1 & $7 / 3$ & 2.5 & 0.7 to 9.9 \\
\hline $\mathrm{H} 4-\mathrm{H} 6$ & $62 / 44$ & 1.6 & 1.004 to 2.5 & $31 / 20$ & 1.8 & 0.97 to 3.4 & $3 / 2$ & 1.6 & 0.3 to 9.9 \\
\hline
\end{tabular}


Table 2 Odds ratios and 95\% confidence interval for malignant brain tumours for the whole study area (H1- $\mathrm{H} 6)$, and urban $(\mathrm{H} 1-\mathrm{H} 3)$ and rural areas $(\mathrm{H} 4-\mathrm{H} 6)$

\begin{tabular}{|c|c|c|c|c|c|c|c|c|c|}
\hline & \multicolumn{3}{|c|}{$>1$ year latency } & \multicolumn{3}{|c|}{$>5$ year latency } & \multicolumn{3}{|c|}{$>10$ year latency } \\
\hline & $\mathrm{Ca} / \mathrm{Co}_{0}$ & OR & $95 \% \mathrm{Cl}$ & $\mathrm{Ca} / \mathrm{Co}_{0}$ & OR & $95 \% \mathrm{Cl}$ & $\mathrm{Ca} / \mathrm{Co}_{0}$ & OR & $95 \% \mathrm{Cl}$ \\
\hline $\begin{array}{l}\text { Analogue } \\
\mathrm{H} 1-\mathrm{H} 6 \\
\mathrm{H} 1-\mathrm{H} 3 \\
\mathrm{H} 4-\mathrm{H} 6\end{array}$ & $\begin{array}{l}110 / 96 \\
81 / 68 \\
29 / 28\end{array}$ & $\begin{array}{l}1.2 \\
1.4 \\
0.9\end{array}$ & $\begin{array}{l}0.8 \text { to } 1.7 \\
0.9 \text { to } 2.1 \\
0.5 \text { to } 1.7\end{array}$ & $\begin{array}{l}71 / 61 \\
55 / 45 \\
16 / 16\end{array}$ & $\begin{array}{l}1.2 \\
1.4 \\
0.9\end{array}$ & $\begin{array}{l}0.8 \text { to } 1.8 \\
0.9 \text { to } 2.2 \\
0.4 \text { to } 2.0\end{array}$ & $\begin{array}{l}34 / 17 \\
25 / 12 \\
9 / 5\end{array}$ & $\begin{array}{l}2.1 \\
2.4 \\
1.7\end{array}$ & $\begin{array}{l}1.1 \text { to } 4.0 \\
1.1 \text { to } 5.1 \\
0.5 \text { to } 5.6\end{array}$ \\
\hline $\begin{array}{l}\text { Digital } \\
\mathrm{H} 1-\mathrm{H} 6 \\
\mathrm{H} 1-\mathrm{H} 3 \\
\mathrm{H} 4-\mathrm{H} 6\end{array}$ & $\begin{array}{l}204 / 167 \\
151 / 132 \\
53 / 35\end{array}$ & $\begin{array}{l}1.2 \\
1.3 \\
1.2\end{array}$ & $\begin{array}{l}0.9 \text { to } 1.6 \\
0.9 \text { to } 1.8 \\
0.7 \text { to } 2.2\end{array}$ & $\begin{array}{l}39 / 24 \\
29 / 23 \\
10 / 1\end{array}$ & $\begin{array}{l}1.7 \\
1.4 \\
8.4\end{array}$ & $\begin{array}{l}0.95 \text { to } 2.9 \\
0.8 \text { to } 2.6 \\
1.02 \text { to } 69\end{array}$ & $\begin{array}{l}- \\
- \\
-\end{array}$ & $\begin{array}{l}- \\
- \\
-\end{array}$ & $\begin{array}{l}- \\
- \\
-\end{array}$ \\
\hline $\begin{array}{l}\text { Cordless } \\
\mathrm{H} 1-\mathrm{H} 6 \\
\mathrm{H} 1-\mathrm{H} 3 \\
\mathrm{H} 4-\mathrm{H} 6\end{array}$ & $\begin{array}{l}179 / 143 \\
126 / 110 \\
53 / 33\end{array}$ & $\begin{array}{l}1.2 \\
1.2 \\
1.3\end{array}$ & $\begin{array}{l}0.9 \text { to } 1.7 \\
0.9 \text { to } 1.8 \\
0.7 \text { to } 2.3\end{array}$ & $\begin{array}{l}69 / 46 \\
51 / 35 \\
18 / 11\end{array}$ & $\begin{array}{l}1.6 \\
1.6 \\
1.4\end{array}$ & $\begin{array}{l}1.02 \text { to } 2.4 \\
0.99 \text { to } 2.7 \\
0.6 \text { to } 3.3\end{array}$ & $\begin{array}{l}3 / 4 \\
2 / 2 \\
1 / 2\end{array}$ & $\begin{array}{l}0.8 \\
1.2 \\
0.3\end{array}$ & $\begin{array}{l}0.2 \text { to } 3.6 \\
0.2 \text { to } 8.7 \\
0.02 \text { to } 3.6\end{array}$ \\
\hline
\end{tabular}

Unconditional logistic regression analysis was used, adjusted for age, sex, and socioeconomic index. Numbers of exposed cases (Ca) and controls (Co) are given. Note that controls with missing cases were not included.

period) was analysed using three time periods, $>1$ year, $>5$ years, and $>10$ years since first use of a cellular or cordless telephone until tumour diagnosis. $\mathrm{Hl}-\mathrm{H} 3$ were classified as urban ( $\mathrm{n}=984$ cases, 1035 controls) and H4-H6 as rural areas ( $n=445$ cases, $n=435$ controls).

\section{RESULTS}

No significant difference existed for cumulative use in hours for cordless or cellular telephones depending on urban or rural area for the cases. If anything, cases in rural areas tended to have shorter cumulative use than cases living in urban areas.

In table 1 results for brain tumours and use of cellular or cordless phones are given for the different geographical areas (urban and rural) as well as overall results. The unexposed group consisted of 713 cases and 757 controls. For analogue phones an increased OR was found in both urban and rural areas. ORs were somewhat higher in rural areas when latency period was considered. For ipsilateral use of analogue phones with >1 year latency period, ORs were 1.7 (95\% CI 1.1 to 2.5 ) for living in urban areas, and 1.6 (95\% CI 0.9 to 2.8) for living in rural areas (data not shown). Regarding digital phones, OR was increased in rural areas, whereas OR for subjects living in urban areas was close to unity. With $>5$ year latency period, OR was significantly increased in rural areas
$(\mathrm{OR}=3.2,95 \% \mathrm{CI} 1.2$ to 8.4$)$. With $>5$ years latency period and $>55$ hours of cumulative use, OR was calculated to be 1.1 (95\% CI 0.7 to 1.9 ) in urban areas compared with 4.2 (95\% CI 1.1 to 16 ) in rural areas. For ipsilateral use of digital phones with $>1$ year latency period, ORs were 1.2 (95\% CI 0.9 to 1.7 ) for living in urban areas, and 1.7 (95\% CI 0.99 to 2.8 ) for living in rural areas (data not shown). For cordless telephones ORs were higher in rural areas than in urban areas, except for $>10$ year latency period, based on low numbers.

Table 2 gives the results for malignant brain tumour cases with corresponding controls. No effect of place of residence was found for analogue or cordless phones. Regarding digital phones, the risk was highest in rural areas using latency period $>5$ years $(\mathrm{OR}=8.4,95 \%$ CI 1.02 to 69$)$, but based on low numbers. In a separate analysis of cases with astrocytoma $(n=415)$, OR was somewhat higher for urban living than for rural for use of analogue cellular telephones or cordless phones. For use of digital phones with $>1$ year latency period, results were: $\mathrm{OR}=1.4(95 \% \mathrm{CI} 0.96$ to 2.2$)$ for urban living, and OR $=1.2$ (95\% CI 0.6 to 2.4 ) for rural living. The results for $>5$ year latency period were: $\mathrm{OR}=1.8(95 \% \mathrm{CI}$ 0.9 to 3.5$)$ ( 26 cases, 19 controls) and OR $=6.6$ (95\% CI 0.8 to 56) ( 8 cases, 1 control) for urban and rural living, respectively (data not shown).

Table 3 Odds ratios and $95 \%$ confidence intervals for benign brain tumours for the whole study area $(\mathrm{H} 1-\mathrm{H} 6)$, and urban $(\mathrm{H} 1-\mathrm{H} 3)$ and rural areas $(\mathrm{H} 4-\mathrm{H} 6)$

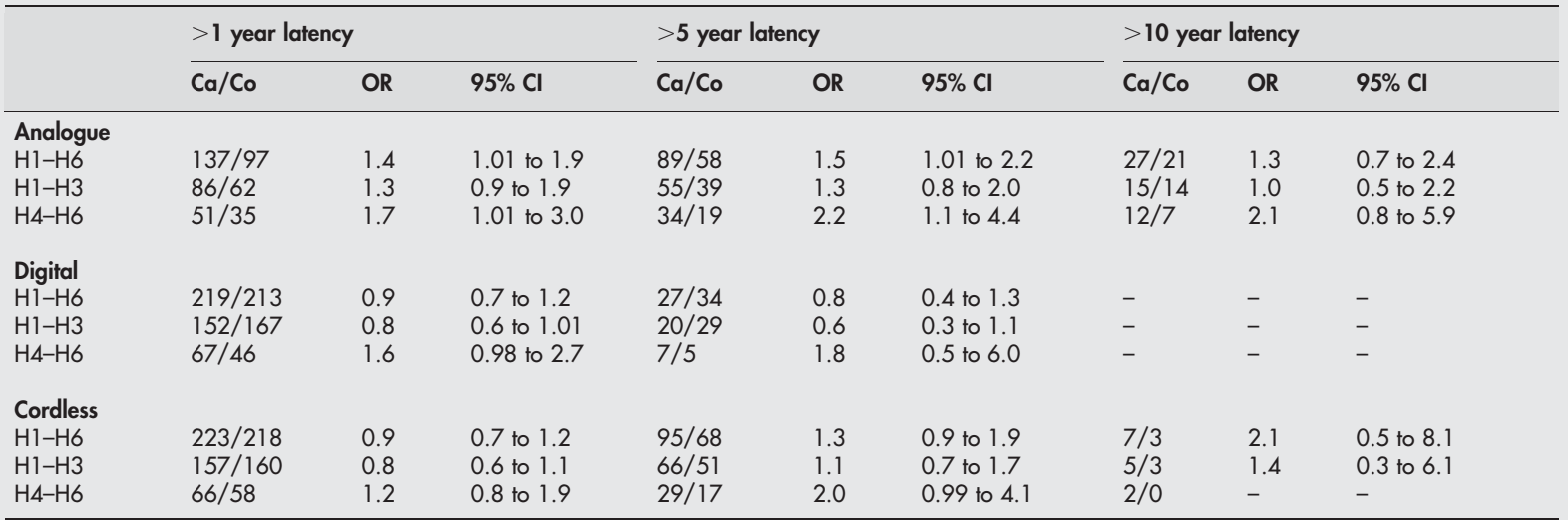

Unconditional logistic regression analysis was used, adjusted for age, sex, and socioeconomic index. Numbers of exposed cases (Ca) and controls (Co) are given. Note that controls with missing cases were not included. 
Table 4 Odds ratios (OR) and 95\% confidence intervals for brain tumours for the whole study area $(\mathrm{H} 1-\mathrm{H} 6)$, and urban $(\mathrm{H} 1-\mathrm{H} 3)$ and rural areas $(\mathrm{H} 4-\mathrm{H} 6)$ for use of one phone type only

\begin{tabular}{|c|c|c|c|c|c|c|c|c|c|}
\hline & \multicolumn{3}{|c|}{$>1$ year latency } & \multicolumn{3}{|c|}{$>5$ year latency } & \multicolumn{3}{|c|}{$>10$ year latency } \\
\hline & $\mathrm{Ca} / \mathrm{Co}$ & OR & $\mathrm{Cl}$ & $\mathrm{Ca} / \mathrm{Co}$ & OR & $\mathrm{Cl}$ & $\mathrm{Ca} / \mathrm{Co}$ & OR & $\mathrm{Cl}$ \\
\hline \multicolumn{10}{|c|}{ Analogue only } \\
\hline $\mathrm{H} 1-\mathrm{H} 6$ & $81 / 72$ & 1.3 & 0.9 to 1.8 & $41 / 27$ & 1.7 & 1.1 to 2.9 & $14 / 6$ & 2.7 & 1.04 to 7.3 \\
\hline $\mathrm{H} 1-\mathrm{H} 3$ & $50 / 37$ & 1.6 & 0.99 to 2.4 & $24 / 13$ & 2.1 & 1.1 to 4.3 & $10 / 3$ & 4.0 & 1.1 to 15 \\
\hline $\mathrm{H} 4-\mathrm{H} 6$ & $31 / 35$ & 1.0 & 0.6 to 1.8 & $17 / 14$ & 1.4 & 0.7 to 3.0 & $4 / 3$ & 1.5 & 0.3 to 6.8 \\
\hline \multicolumn{10}{|c|}{ Digital only } \\
\hline $\mathrm{Hl}-\mathrm{H} 6$ & $188 / 195$ & 1.0 & 0.8 to 1.3 & $27 / 26$ & 1.2 & 0.7 to 2.0 & - & - & - \\
\hline $\mathrm{H} 1-\mathrm{H} 3$ & $128 / 149$ & 0.9 & 0.7 to 1.2 & $15 / 24$ & 0.7 & 0.4 to 1.3 & - & - & - \\
\hline $\mathrm{H} 4-\mathrm{H} 6$ & $60 / 46$ & 1.4 & 0.9 to 2.2 & $12 / 2$ & 6.9 & 1.5 to 32 & - & - & - \\
\hline \multicolumn{10}{|c|}{ Cordless only } \\
\hline $\mathrm{Hl}-\mathrm{H} 6$ & $159 / 169$ & 1.0 & 0.8 to 1.3 & $56 / 36$ & 1.7 & 1.1 to 2.6 & $2 / 2$ & 1.0 & 0.1 to 7.4 \\
\hline $\mathrm{H} 1-\mathrm{H} 3$ & $109 / 121$ & 1.0 & 0.7 to 1.3 & $38 / 27$ & 1.5 & 0.9 to 2.5 & $1 / 2$ & 0.5 & 0.1 to 5.3 \\
\hline $\mathrm{H} 4-\mathrm{H} 6$ & $50 / 48$ & 1.1 & 0.7 to 1.8 & $18 / 9$ & 2.3 & 0.97 to 5.3 & $1 / 0$ & - & - \\
\hline
\end{tabular}

Table 3 shows results for benign brain tumours only. For all phone types ORs were highest in rural areas, although some of the calculations were based on low numbers. As has been shown previously, the increased risk was found for acoustic neuroma but not for meningioma. ${ }^{2}$

Table 4 gives results for use of either analogue, digital, or cordless telephones. Thus, subjects who had used more than one phone type were not included. Analogue phones yielded significantly increased ORs for $>5$ year and $>10$ year latency period, respectively. There was no effect of urban versus rural residence. However, the results were based on rather low numbers, especially in the category with $>10$ year latency period. Regarding digital phones OR was highest in rural areas, but based on low numbers. Thus, for $>5$ year latency period OR was calculated in rural areas to be 6.9 (95\% CI 1.5 to 32). However, for cordless phones there was also a tendency for higher ORs in rural areas in the group with $>5$ year latency period.

\section{DISCUSSION}

In a study on acoustic neuroma the risk estimate was higher in urban areas compared with rural areas. ${ }^{7}$ However, the results were based on low numbers and have been criticised for inclusion of cases not in agreement with the Swedish Cancer Registry, different geographical areas for cases and controls, and inconsistent numbers in tables. ${ }^{8}$ Our study is the first with a substantial number of cases and controls where the place of residence for cases and controls has been considered in the analysis of an association between use of cellular telephones and the risk for brain tumours. The Swedish population register covers the whole population. The municipality for each person is registered. We used that information in combination with the classification of the municipalities in homogeneity regions by Statistics Sweden. Of course this study would benefit from more categories of homogeneity instead of only two summary groups. However, few subjects (95 cases, 111 controls) lived in the most sparsely populated areas, H5 and H6, making statistical analysis less meaningful in that group.

Interestingly, we found a somewhat higher risk for brain tumours for cases living in rural areas than in urban areas for use of NMT phones. ORs were also increased among urban inhabitants. This was not explained by socioeconomic factors since the results were adjusted for SEI code. However, when we analysed use of analogue phones only, ORs were highest in urban areas. Thus, no clear effect of place of residence was seen for analogue phones. This may be explained by the fact that APC was not initially used for this phone system. ${ }^{1}$ We have no information when APC was introduced, if at all, for analogue phones during our study period.

For use of GSM phones we found a clear effect of urban versus rural areas. In fact, we only found an increased risk for rural living and this could not be explained by longer phone calls among these cases. Dose-response calculations seemed to further support the result. Analysis of digital phones as the only used phone type showed a similar pattern, with highest ORs among rural inhabitants. These results may be of importance in future studies of brain tumour risk for digital phones. Thus our results, if confirmed in other studies, indicate that the risk of microwave exposure from digital phones is lower in areas with a short distance to base stations due to APC.

When we analysed malignant brain tumours separately, ORs were found to be highest in rural areas for digital phones using $>5$ year latency period. These results were based on low numbers, only one control, and must thus be interpreted with caution. Of interest, however, is the fact that no clear pattern was found for analogue or cordless phones. Regarding benign tumours, ORs were highest in rural areas regardless of phone type. Since these results were mainly based on the increased risk for acoustic neuroma, one possibility is that a confounding factor associated with place of living may exist, although this is as yet unknown.

Clearly our results support the notion that exposure may differ between geographical areas. However, these results refer to Sweden and there is no information on the exact difference between different geographical areas. Furthermore, the published results only refer to the GSM network. ${ }^{1}$ Our findings indicate that in future studies place of residence should be considered in assessment of exposure to microwaves from cellular telephones, although the results of this study must be interpreted with caution due to the low numbers in some of the calculations. From a precautionary perspective, users of cellular telephones should select phones with low SAR, since differences in SAR between phone types may be larger than output power levels depending on whether the users live in urban or rural areas.

\section{Authors' affiliations}

L Hardell, Department of Oncology, University Hospital, and Department of Natural Sciences, Orebro University, Örebro, Sweden M Carlberg, Department of Oncology, University Hospital, Örebro, Sweden 
K Hansson Mild, National Institute for Working Life, Umeå and Department of Natural Sciences, Örebro University, Örebro, Sweden

Funding: Supported by grants from Cancer- och Allergifonden, Örebro Cancer Fund, and Nyckelfonden.

Competing interests: none declared

\section{REFERENCES}

1 Lönn S, Forssén U, Vecchia $P$, et al. Output power levels from mobile phones in different geographical areas; implications for exposure assessment. Occup Environ Med 2004;61:769-72.

2 Hardell L, Hansson Mild K, Carlberg M. Further aspects on cellular and cordless telephones and brain tumours. Int J Oncol 2003;22:399-407.
3 Hansson Mild K, Hardell L, Kundi M, et al. Mobile telephones and cancer: is there really no evidence of an association? Int J Molecular Med 2003;12:67-72.

4 Hardell L, Hallquist A, Hansson Mild K, et al. No association between the use of cellular or cordless telephones and salivary gland tumours. Occup Environ Med 2004;61:675-9

5 Kundi M, Hansson Mild K, Hardell L, et al. Mobile telephones and cancer-a review of epidemiological evidence. J Toxicol Environ Health $B$ 2004;7:351-84.

6 Statistics Sweden. Numerical codes by region for various Swedish subdivisions. http://www.scb.se/Grupp/regionalt/rg0104//_regioner.pdf (accessed 2 September 2004).

7 Lönn S, Ahlbom A, Hall P, et al. Mobile phone use and the risk for acoustic neuroma. Epidemiology 2004;15:653-9.

8 Hardell L, Hansson Mild K. Mobile phone use and the risk for acoustic neuroma. Epidemiology. In press.

\section{Clinical Evidence - Call for contributors}

Clinical Evidence is a regularly updated evidence-based journal available worldwide both as a paper version and on the internet. Clinical Evidence needs to recruit a number of new contributors. Contributors are healthcare professionals or epidemiologists with experience in evidence-based medicine and the ability to write in a concise and structured way.

Areas for which we are currently seeking authors:

- Child health: nocturnal enuresis

- Eye disorders: bacterial conjunctivitis

- Male health: prostate cancer (metastatic)

- Women's health: pre-menstrual syndrome; pyelonephritis in non-pregnant women

However, we are always looking for others, so do not let this list discourage you.

Being a contributor involves:

- Selecting from a validated, screened search (performed by in-house Information Specialists) epidemiologically sound studies for inclusion.

- Documenting your decisions about which studies to include on an inclusion and exclusion form, which we keep on file.

- Writing the text to a highly structured template (about 1500-3000 words), using evidence from the final studies chosen, within 8-10 weeks of receiving the literature search.

- Working with Clinical Evidence editors to ensure that the final text meets epidemiological and style standards.

- Updating the text every six months using any new, sound evidence that becomes available. The Clinical Evidence in-house team will conduct the searches for contributors; your task is simply to filter out high quality studies and incorporate them in the existing text.

- To expand the topic to include a new question about once every 12-18 months.

If you would like to become a contributor for Clinical Evidence or require more information about what this involves please send your contact details and a copy of your CV, clearly stating the clinical area you are interested in, to Klara Brunnhuber (kbrunnhuber@ bmigroup.com).

\section{Call for peer reviewers}

Clinical Evidence also needs to recruit a number of new peer reviewers specifically with an interest in the clinical areas stated above, and also others related to general practice. Peer reviewers are healthcare professionals or epidemiologists with experience in evidence-based medicine. As a peer reviewer you would be asked for your views on the clinical relevance, validity, and accessibility of specific topics within the journal, and their usefulness to the intended audience (international generalists and healthcare professionals, possibly with limited statistical knowledge). Topics are usually 1500-3000 words in length and we would ask you to review between 2-5 topics per year. The peer review process takes place throughout the year, and our furnaround time for each review is ideally 10-14 days.

If you are interested in becoming a peer reviewer for Clinical Evidence, please complete the peer review questionnaire at www.clinicalevidence.com or contact Klara Brunnhuber (kbrunnhuber@bmigroup.com). 